\title{
IMPLEMENTAÇÃO DAS DIRETRIZES DA OCDE PARA AS EMPRESAS MULTINACIONAIS NO BRASIL: AVANÇOS E DESAFIOS ${ }^{\wedge}$
}

Hevellyn Albres²

\begin{abstract}
SINOPSE
As Diretrizes da OCDE para as Empresas Multinacionais (Diretrizes) podem ser consideradas o principal instrumento internacional de conduta empresarial responsável (CER). No Brasil, sua implementação é responsabilidade de um grupo de trabalho interministerial (GTI) coordenado pelo Ministério da Economia, chamado PCN Brasil. Este artigo discute a implementação das Diretrizes por meio do PCN Brasil, indicando avanços alcançados em seus quase vinte anos de existência e desafios e oportunidades remanescentes. 0 texto é composto pelos seguintes itens: i) seção introdutória sobre o que são as Diretrizes e quais são as funções dos PCNs; ii) principais características dos PCNs e sua implementação no Brasil; e iii) desafios e oportunidades para a implementação das Diretrizes pelo PCN Brasil.
\end{abstract}

Palavras-chave: conduta empresarial responsável; Diretrizes da OCDE para as Empresas Multinacionais; Ponto de Contato Nacional; PCN Brasil.

\begin{abstract}
The Organization for Economic Co-operation and Development (OECD) Guidelines for Multinational Enterprises can be considered the main international instrument for responsible business conduct (RBC). In Brazil, its implementation is the responsibility of an inter-ministerial working group coordinated by the Ministry of Economy, called National Contact Point (NCP) Brazil. This article discusses the implementation of the Guidelines by the NCP Brazil, indicating progress achieved over its nearly twenty years of existence and the remaining challenges and opportunities. The article is structured as follows: i) an introductory section that briefly presents the main features of the Guidelines and the NCPs' roles; ii) a section presenting the key characteristics of the NCPs and their implementation in Brazil; and iii) a third section that highlights some challenges and opportunities for the implementation of the Guidelines by the NCP Brazil.
\end{abstract}

Keywords: responsible business conduct; OECD Guidelines for Multinational Enterprises; National Contact Point; NCP Brazil. JEL: F51; F53.

Artigo recebido em 28/2/2021 e aprovado em 22/3/2021.

DOl: http://dx.doi.org/10.38116/bepi29art2

\section{INTRODUÇÃO}

Conduta empresarial responsável (CER) é um tema de crescente relevância no cenário internacional, associado a discussôes como desenvolvimento sustentável, sustentabilidade e compliance, ou integridade. Podemos dizer que a CER estabelece a expectativa de que todas as empresas - independentemente de sua natureza, propriedade, porte ou setor - evitem e enderecem os impactos negativos de suas operaçóes e contribuam para o desenvolvimento sustentável dos países em que operam (OECD, 2021a).

\footnotetext{
1. As opiniões expressas neste artigo não refletem necessariamente a visão do Ministério da Economia ou do PCN Brasil.

2. Servidora do Ministério da Economia, atualmente responsável pela equipe de Coordenação e Secretaria Executiva do Ponto de Contato Nacional (PCN) Brasil para as Diretrizes da Organização para a Cooperação e o Desenvolvimento Econômico (OCDE) para as Empresas Multinacionais; mestre em políticas públicas e desenvolvimento pelo Ipea; e mestre em relações internacionais pela Universidade de Brasília (UnB).
} 
CER também envolve obrigações governamentais de incentivo e monitoramento desse comportamento, conforme estabelecem os três principais instrumentos internacionais na área: as Diretrizes da Organização para a Cooperação e o Desenvolvimento Econômico (OCDE) para Empresas Multinacionais (Diretrizes); os Princípios Orientadores da Organização das Naçôes Unidas (ONU) sobre Direitos Humanos e Empresas (Princípios Orientadores da ONU); e a Declaração Tripartite de Princípios sobre Empresas Multinacionais e Política Social da Organização Internacional do Trabalho (OIT) (Declaração Tripartite da OIT).

Entre os instrumentos internacionais para a CER, as Diretrizes destacam-se como o único código de CER abrangente e multilateralmente acordado que conta com o compromisso governamental para sua promoção (OECD, 2021b). Outra característica que as diferenciam é ter o suporte dos chamados Pontos de Contato Nacionais (PCNs), que são agências que os governos aderentes têm a obrigação de estabelecer para promover suas recomendaçóes. Eles dão suporte às partes interessadas para a implementaçáo das Diretrizes e fornecem uma plataforma de mediaçáo e conciliaçáo para a resoluçáo de questôes práticas que possam surgir sobre seu conteúdo (OECD, 2011).

No que diz respeito ao escopo, as Diretrizes são o instrumento internacional mais abrangente sobre CER, cobrindo todas as áreas-chave da responsabilidade empresarial (OECD, 2021b). Os temas cobertos, cada um em um capítulo dedicado, são: i) conceito e princípios; ii) políticas gerais; iii) divulgação; iv) direitos humanos; v) emprego e relaçóes empresariais; vi) meio ambiente; vii) combate à corrupção, à solicitação de suborno e à extorsão; viii) interesses do consumidor; ix) ciência e tecnologia; x) concorrência; e xi) tributação (OECD, 2011).

As Diretrizes refletem uma expectativa dos governos de que as empresas ajam de forma responsável. Elas fornecem princípios e padróes não vinculantes de CER para um contexto global, mas também consistentes com leis nacionais e padróes internacionais aplicáveis (OECD, 2021b). Trata-se de recomendaçóes bastante amplas direcionadas pelos governos aderentes para empresas que atuam em seus territórios ou a partir deles (OECD, 2011).

Vale mencionar que as Diretrizes são um anexo da Declaração da OCDE sobre Investimento Internacional e Empresas Multinacionais (Declaração da OCDE), um amplo compromisso político adotado em 1976 visando a facilitar o investimento direto entre os Estados-parte. Por meio dela, os países da OCDE e demais aderentes comprometem-se a buscar construir um ambiente aberto e transparente para o investimento internacional, além de encorajar as empresas multinacionais a contribuir para a obtenção de progressos econômicos e sociais (OECD, 2011).

As Diretrizes passaram por quatro revisóes $(1979,1984,2000$ e 2011) e uma atualização (1991) até hoje. Na última revisão, de 2011, o grande destaque foi a inclusáo de um capítulo para os direitos humanos, consistente com os Princípios Orientadores da ONU, que foram publicados naquele mesmo ano. Além disso, foi incluída uma abordagem nova e abrangente para a devida diligência na cadeia de suprimentos; ${ }^{3}$ houve incorporação de uma agenda proativa para auxiliar as empresas na implementação das Diretrizes; e foram realizadas atualizaçóes nos capítulos especializados e nas orientaçóes procedimentais para os PCNs

3. De acordo com a OCDE, a devida diligência baseada em riscos é um elemento-chave da CER e consiste em um processo pelo qual as empresas identificam, previnem e mitigam os impactos negativos reais e potenciais decorrentes de suas operações e prestam contas sobre como esses impactos são endereçados (OECD, 2020a). Em 2018, foi aprovado o guia da OCDE sobre devida diligência em CER, que se aplica a todas as empresas em todos os setores. Adicionalmente, foram publicados guias específicos para os setores mineral, extrativo, têxtil/calçados e agrícola, além de orientações para o setor financeiro. 
(OECD, 2011). Em 2020, iniciou-se um exercício de revisão que poderá implicar uma nova revisão das Diretrizes entre 2021 e 2022 (OECD, 2021a).

As três ferramentas principais para a implementação das Diretrizes são: i) o próprio secretariado da OCDE; ii) o Comitê de Investimentos da OCDE, especificamente por meio do grupo de trabalho (GT) de CER; e iii) os governos aderentes, com destaque para o estabelecimento dos PCNs (OECD, 2017). Os PCNs se reúnem em uma Rede dos PCNs, que alcança todos os aderentes, e também em grupos regionais, como a Rede dos PCNs da América Latina. Também merece atenção o fato de que as Diretrizes foram construídas, revisadas, e sua implementação é supervisionada não apenas por atores governamentais, mas por um conjunto de partes interessadas que representam o setor empresarial (Business at OECD - Biac), os sindicatos (Trade Union Advisory Committee - Tuac) e o terceiro setor (OECD Watch).

Dado o escopo deste trabalho, focalizamos a implementação das Diretrizes por meio dos PCNs. Realizada esta breve introdução, apresentamos, na seçáo seguinte, informaçóes fundamentais sobre a estrutura, o arranjo institucional e as funçôes dos PCNs, indicando de que modo são implementados no Brasil. Na terceira seção, analisamos alguns desafios e oportunidades para uma atuação otimizada do PCN Brasil em relação a esses elementos. Por fim, tecemos nossas consideraçóes finais.

\section{PCNs: PRINCIPAIS CARACTERÍSTICAS E IMPLEMENTAÇÃO NO BRASIL}

Os PCNs são estruturas estabelecidas pelos governos para promover as Diretrizes e lidar com casos de inobservância pelas empresas (chamados instâncias específicas), como um mecanismo de reclamação não judicial. Eles são considerados um mecanismo único de implementação de CER e têm dado suporte ao acesso à remediação em escala global (OECD, 2021a). Hoje há cinquenta PCNs estabelecidos, distribuídos entre América, Europa, Ásia, África e Oceania. ${ }^{4}$

Os PCNs foram estabelecidos na revisão de 1984 das Diretrizes, primeiramente com o papel de divulgar o instrumento e esclarecer dúvidas sobre seu conteúdo. Em 2000, houve uma significativa alteração nesse mandato, que passou a incluir o tratamento das instâncias específicas (OECD, 2020b). A partir de 2019, tem se consolidado atribuição adicional relacionada à coordenação e à coerência política em CER, além da crescente relevância dos instrumentos de devida diligência em CER (OECD, 2019).

Há um grande número de materiais disponíveis sobre os PCNs, sobretudo produzidos pela própria OCDE. Não pretendemos aqui realizar a revisão bibliográfica desse material, mas olhar de forma prática para como os PCNs estão estruturados e funcionam efetivamente. Com esse objetivo, o Questionário Anual de Reporte dos $\mathrm{PCNs}^{5}$ (Questionário) será o nosso ponto de partida para a definição das informaçóes principais a serem apresentadas e que depois darão amparo à nossa análise sobre os desafios e oportunidades do PCN Brasil.

Iniciamos esta seção tratando da estrutura e do arranjo institucional dos PCNs. Em seguida, observamos cada uma das três funçóes principais dos PCNs: informação e promoção das Diretrizes

\footnotetext{
4. A lista completa dos PCNs está disponível em: <http://mneguidelines.oecd.org/ncps/>. Dados verificados em 20 de junho de 2021.

5. Esses questionários alimentam os relatórios anuais sobre as Diretrizes, pelos quais estatísticas e tendências sobre as atividades dos PCNs são apresentadas ao Conselho da OCDE todos os anos (OECD, 2020b). Estão disponíveis na página eletrônica do PCN os Questionários de 2013 a 2020: <https://gov.br/pcn>.
} 
e instrumentos relacionados; tratamento de instâncias específicas de inobservância das Diretrizes; e coerência política em CER. Para cada ponto, realizamos uma breve introdução contextualizando o leitor e, depois, focalizamos a realidade do PCN Brasil.

\subsection{Estrutura e arranjo institucional}

Os governos aderentes têm flexibilidade na organização de seus PCNs, desde que o arranjo adotado forneça uma base eficaz para lidar com todas as questóes cobertas pelas Diretrizes e permita que o PCN atue de maneira imparcial e com accountability (OECD, 2017). Para orientar essa estruturação, as Diretrizes estabelecem critérios de visibilidade, acessibilidade, transparência e accountability a serem considerados para a garantia de equivalência funcional ${ }^{6}$ entre os PCNs (OECD, 2011).

Entre as estruturas que um PCN pode adotar, a OCDE identificou quatro padróes emergentes, além da possibilidade de um formato híbrido. A maioria dos PCNs (19) é estabelecida como agência única, e 14 deles, inclusive o Brasil, têm o formato interministerial (dois ou mais órgãos). Nove PCNs adotam o formato multistakeholder, contemplando atores do governo, organizaçóes empresariais, sindicatos e/ou organizações não governamentais (ONGs). Quatro PCNs são estruturados com base em especialistas independentes (expert-based) e dois têm formato híbrido, que combina mais de um dos anteriores (OECD, 2020b).

Independentemente do formato, a OCDE lembra lembra que é imprescindível que os PCNs tenham a confiança das partes interessadas (OECD, 2020b). Para isso, a sugestão é que esses atores sejam incluídos na estrutura dos $\mathrm{PCNs}$, o que poderia ser feito: tornando os PCNs órgáos multistakeholder; incluindo órgãos consultivos nos PCNs que têm estrutura de agência única ou interministerial; ou permitindo que as partes interessadas nomeiem os especialistas independentes, no caso dos PCNs baseados em especialistas.

No que diz respeito à estrutura e ao arranjo institucional, o Questionário focaliza: i) a estrutura, localização ${ }^{7}$ e composição do PCN; ii) a existência e forma de funcionamento de órgão(s) consultivo(s); iii) a disponibilidade e alocação dos recursos humanos e financeiros; e iv) o reporte de suas atividades (Brasil, 2020a). Em seguida, observamos a situação do PCN Brasil em relação a cada um desses pontos.

\subsubsection{Avanço da implementação no Brasil}

No que diz respeito à estrutura, localização e composição, o PCN Brasil evoluiu desde sua criação de um formato de agência única para um interministerial. Ele foi criado em 2003, por meio da Portaria do Ministério da Fazenda (MF) no 92, de 12 de maio de 2003. Naquele momento, foi estruturado como órgão de agência única, na Secretaria de Assuntos Internacionais (Sain) do MF, podendo ser auxiliado por outros órgáos governamentais (Brasil, 2003).

Aproximadamente dez anos após sua criação, e no contexto da última revisão das Diretrizes, houve uma significativa reestruturação do PCN. Em 2013, foi publicada a Portaria Interministerial no 37 , de 19 de fevereiro de 2013, que constituiu o PCN como grupo interministerial, ainda coordenado

6. As Diretrizes não trazem uma definição do que seja a equivalência funcional. 0 intuito é que todos os PCNs operem de maneira uniforme, ainda que não possuam a mesma estrutura ou regras de procedimento. De acordo com a OCDE, "para garantir que todos os PCNs operem de modo comparável, o conceito de 'equivalência funcional' é utilizado" (OECD, 2017, tradução nossa).

7. A localização consiste no secretariado no caso dos PCNs que não adotam o formato de agência única. 
e secretariado pela Sain/MF, e composto por outros dez órgãos ${ }^{8}$ (Brasil, 2013a). De acordo com o Questionário daquele ano, esperava-se que, com a participação obrigatória de outros órgãos além do então MF, houvesse maior sensação de pertencimento por essas agências governamentais e a divulgação das Diretrizes no âmbito do governo melhorasse (Brasil, 2013b).

Por fim, em 2019, acompanhando outras modificaçóes no governo federal, temos uma nova alteração de composição e localização, com a edição do Decreto no 9.874, de 27 de junho de 2019 (Brasil, 2019a). O PCN mantém a estrutura de grupo de trabalho interministerial (GTI), mas altera parte de sua composição9 e sua localização passa a estar na Secretaria Especial de Comércio Exterior e Assuntos Internacionais do Ministério da Economia (Secint/ME), mais especificamente na Secretaria Executiva da Câmara de Comércio Exterior (Camex), a cargo da Subsecretaria de Investimentos Estrangeiros (Brasil, 2019b). Pode-se considerar que o decreto representou um ganho na institucionalização do PCN, mas também houve alguns engessamentos que podem ter prejudicado sua efetividade, como discutiremos na última seção.

A evolução da composição do GTI do PCN está disponível na figura 1.

\section{FIGURA 1}

\section{Composição do PCN Brasil}

\begin{tabular}{|c|c|c|c|c|}
\hline ồ $\quad$ MF & $\sum_{i}^{m}$ & $\begin{array}{l}\text { BCB } \\
\text { CGU } \\
\text { MCTI } \\
\text { MDIC } \\
\text { MF (coordenação) } \\
\text { MJ } \\
\text { MMA } \\
\text { MPOG } \\
\text { MRE } \\
\text { MTE } \\
\text { SDH-PR }\end{array}$ & $\grave{N}^{\circ}$ & $\begin{array}{l}\text { BCB } \\
\text { CGU } \\
\text { MJSP } \\
\text { MMA } \\
\text { MME } \\
\text { MMFDH } \\
\text { MRE } \\
\text { Secint/ME } \\
\text { (coordenação) } \\
\text { Sepec/ME } \\
\text { SEPRT/ME }\end{array}$ \\
\hline
\end{tabular}

Fonte: Brasil (2003; 2013a; 2019a).

Elaboração da autora.

Em relação à disponibilidade e à alocação dos recursos humanos e financeiros, o Brasil está entre os $53 \%$ dos PCNs que possuem funcionários trabalhando em tempo integral com o tema (OECD, 2020b). De fato, vemos um avanço substantivo de 2013, quando o PCN reporta não ter qualquer funcionário em tempo integral, para 2020, em que declara ter quatro funcionários em tempo integral

8. Os seguintes órgãos foram incluídos como membros do PCN: Banco Central do Brasil (BCB); Controladoria-Geral da União (CGU); Ministério da Ciência, Tecnologia e Inovação (MCTI); Ministério da Justiça (MJ); Ministério das Relações Exteriores (MRE); Ministério do Desenvolvimento, Indústria e Comércio Exterior (MDIC); Ministério do Meio Ambiente (MMA); Ministério do Planejamento, Orçamento e Gestão (MPOG); Ministério do Trabalho e Emprego (MTE); e Secretaria de Direitos Humanos da Presidência da República (SDH/PR) (Brasil, 2013a). Os órgãos foram escolhidos de acordo com sua expertise nos temas cobertos pelas Diretrizes (Brasil, 2013b).

9. No formato atual, a composição do PCN é a seguinte: Secint/ME; Secretaria Especial de Previdência e Trabalho (SEPRT/ME); Secretaria Especial de Produtividade, Emprego e Competitividade (Sepec/ME); Ministério da Justiça e Segurança Pública (MJSP); Ministério de Minas e Energia (MME); MMA; CGU; Ministério da Mulher, da Família e dos Direitos Humanos (MMFDH); e BCB (Brasil, 2019a). 
e mais um em tempo parcial (Brasil, 2013b; 2020a). Restam, porém, desafios, dadas as dimensões e complexidades do país e dado o aumento das funçôes dos PCNs, como exploraremos na última seção.

Quanto à existência e à forma de funcionamento de órgão(s) consultivo(s), o PCN Brasil não tem esse tipo de estrutura no momento, algo que discutiremos nos desafios e oportunidades. Por fim, quanto à accountability, reporta-se anualmente à OCDE e semestralmente ao Comitê Nacional de Investimentos (Coninv), colegiado que supervisiona as atividades do PCN (Brasil, 2020b).

\subsection{Informação e promoção das Diretrizes e instrumentos relacionados}

No que diz respeito à promoção, espera-se que os PCNs divulguem as Diretrizes para as empresas que atuem no seu país ou a partir dele, bem como para outras partes interessadas, e tirem dúvidas sobre seu conteúdo. Ademais, a partir de 2018, a OCDE vem intensificando sua atuação em devida diligência para CER. De acordo com a OCDE, os PCNs desempenham um papel-chave na promoção do uso dos guias de devida diligência, geral e setoriais (OECD, 2019a).

No eixo de promoção, o Questionário traz dois itens principais: sítio eletrônico e atividades promocionais. O sítio eletrônico deve trazer informaçóes sobre: i) as Diretrizes e o papel dos PCNs; ii) instâncias específicas; iii) atividades promocionais; e iv) contatos. Quanto às atividades promocionais, são considerados: i) plano promocional; ii) organização ou coorganizaçáo de eventos; iii) realizaçáo de apresentaçôes; iv) uso de redes sociais; v) realização de reunião multistakeholder; vi) treinamento para a comunidade empresarial; vii) promoção para comunidade empresarial, ONGs, sindicatos, governo, embaixadas no exterior, agências de promoçáo de investimento; e viii) atividades focadas nos guias de devida diligência (Brasil, 2020a).

\subsubsection{Avanço da implementação no Brasil}

Quanto às atividades promocionais, o PCN Brasil tem uma atuação bastante irregular, ainda que não esteja entre os PCNs com melhor ou pior desempenho. Em 2019, por exemplo, o PCN Brasil havia organizado nove eventos e participado de outros três organizados por parceiros. No mesmo período, o PCN França organizou 40 eventos e participou de outros 27, enquanto diversos PCNs (Egito, Estônia, Islândia, Cazaquistão, República Eslovaca) não organizaram nem participaram de qualquer evento ${ }^{10}$ (OECD, 2019).

Deficiências também aparecem ao analisar outros pontos sobre a seção de informação e promoção do Questionário. Por exemplo, a partir de 2016, o documento passou a incluir uma pergunta sobre a realização de treinamento para a comunidade empresarial sobre as Diretrizes - o PCN Brasil nunca reportou a realização de tais atividades. $\mathrm{O}$ mesmo ocorre com a realização de reunião multistakeholder ${ }^{11}$ (Brasil, 2016a; 2017; 2018; 2019b; 2020a).

A página eletrônica do $\mathrm{PCN}$ Brasil, ${ }^{12}$ por sua vez, atende à maior parte dos critérios do Questionário, tendo como exceção o item referente às atividades promocionais. Em relação a esse ponto, é esperado, por exemplo, que o PCN possua e divulgue um plano de comunicação. Ainda que o PCN Brasil

10. Para a tabela completa, consultar OECD (2020b, p. 61-62).

11. Em 2019, o PCN reporta a realização de reunião multistakeholder, mas informações a seu respeito não são documentadas nos anexos das atividades promocionais.

12. Disponível em: <https://gov.br/pen>. 
tenha reportado a existência do plano na maior parte das respostas aos Questionários durante nosso período de análise, ele não tem sido divulgado ${ }^{13}$ (Brasil, 2013b; 2014; 2015; 2017; 2018; 2020a).

\subsection{Tratamento de instâncias específicas de inobservância das Diretrizes}

Quanto à atuação como mecanismo de reclamação não judicial, o PCN fornece uma plataforma de mediação e/ou conciliação para a resolução de questôes relacionadas à inobservância das Diretrizes. De forma rápida, a OCDE prevê que o tratamento das instâncias específicas passa por três etapas e tem um prazo indicativo de doze meses para conclusão (OECD, 2011). Como veremos ao tratar dos desafios, o cumprimento desse prazo é um desafio comum na Rede dos PCNs e se aplica também ao PCN Brasil.

Uma avaliação inicial deve ser realizada em até três meses, fase em que o PCN analisa se as questóes trazidas pelo alegante merecem exame mais aprofundado e aceita o caso ou publica um comunicado explicando por que não foi aceito. A segunda etapa, com duração estimada de seis meses, é aquela em que o PCN oferece seus bons ofícios (diálogo, mediação, conciliação) ao alegante e à empresa alegada visando à resolução das questóes trazidas. Por fim, a terceira etapa, a ser realizada em até três meses, contempla a conclusão do procedimento, com a publicação de um comunicado ou relatório explicando as questóes que foram trazidas ao PCN, o suporte oferecido e os resultados alcançados (OECD, 2011).

O Questionário analisa o tema das instâncias específicas quanto a: i) regras de procedimentos para o tratamento das instâncias; ii) aspectos práticos desse tratamento, como treinamento e contratação de mediadores; e iii) reporte das instâncias (Brasil, 2020a). Nesses itens, a OCDE busca verificar se os PCNs estão agindo de acordo com os princípios orientadores para instâncias específicas: imparcialidade no tratamento, previsibilidade sobre os procedimentos e o que pode oferecer, equitabilidade entre as partes na condução do processo e operação de forma compatível com as Diretrizes (OECD, 2011).

\subsubsection{Avanço da implementação no Brasil}

Quanto às regras de procedimentos, em 2012, o PCN publicou a Resoluçáo PCN no 1, de 14 de setembro de 2012, detalhando o tratamento das instâncias específicas. Ainda que se tratasse de um documento simplificado, tal publicação é relevante, dado que é o primeiro documento desse tipo publicado pelo PCN Brasil e auxilia a atender critérios para a equivalência funcional entre os PCNs (Brasil, 2012). O normativo foi revogado pela Resoluçáo PCN no 1, de 16 de novembro de 2016, que teve como única alteração substantiva a da estrutura do PCN, que havia passado a ser constituído como GTI (Brasil, 2016a).

Finalmente, em 2020, houve uma alteração mais significativa dos procedimentos, por meio da Resolução PCN no 1, de 3 de março de 2020, que estabelece o Manual de Procedimentos para as Instâncias Especificas do Ponto de Contato Nacional. O manual traz mais detalhes sobre alguns pontos já adotados nas resoluçóes anteriores, como prazos e desistência, além de tratar de temas novos, como o acompanhamento dos compromissos estabelecidos pelas partes ou as recomendaçóes emitidas pelo PCN após a publicação da declaração final. O documento também apresenta aperfeiçoamentos em 
termos de estrutura, como a inclusão de um glossário e de um anexo com formulário para a submissão de alegação de inobservância (Brasil, 2020b).

De forma geral, os procedimentos do PCN Brasil estão alinhados com o previsto pela OCDE: possuem como fases principais a avaliação inicial (três meses), os bons ofícios (seis meses) e a conclusão (três meses), tendo como prazo indicativo a realizaçáo de todo o processo em até doze meses. Há algumas peculiaridades, como a participação de um relator na análise dos casos, uma fase adicional de admissibilidade e a não diferenciação entre comunicado e relatório, realizando a conclusão sempre por uma declaração final (Brasil, 2020b).

De maneira sintética, o processo começa com a submissão da alegação de inobservância pelo alegante. ${ }^{14}$ Em seguida, inicia-se a avaliação inicial, ${ }^{15}$ que tem três marcos importantes: uma análise de admissibilidade realizada pelo coordenador do PCN (etapa náo contemplada nos procedimentos da OCDE); a designação de um relator para a instância; e a realização da avaliaçáo inicial por esse relator, com aprovaçáo posterior pelo GTI do PCN. O relator é apontado pelo coordenador do PCN, sendo preferencialmente um representante do órgão do GTI responsável pela temática abordada na instância específica (Brasil, 2020b).

Caso a instância seja admitida e aceita, o relator poderá recomendar seu encaminhamento para os bons ofícios. ${ }^{16}$ Essa fase crucial da instância contempla uma preparação prévia pelo PCN e a oferta de bons ofícios, que deve ser aceita tanto pelo alegante quanto pela empresa alegada para ter prosseguimento. Caso a oferta seja aceita, as partes devem, ainda, aceitar o mediador ofertado pelo PCN. Este será será preferencialmente um membro do GTI, mas também pode constar de uma lista de mediadores pro bono a ser constituída por meio de um chamamento público. Em seguida, é acordado um plano de trabalho a ser seguido durante a mediação, e esta é conduzida pelo mediador (Brasil, 2020b).

A última etapa é a conclusão do procedimento de tratamento de instâncias, ${ }^{17}$ que, para o caso do PCN Brasil, sempre implica a emissão de uma declaraçáo final. ${ }^{18}$ Esse documento, que descreve o processo realizado, é elaborado pelo relator, revisado pelas partes e aprovado pelo GTI do PCN antes de sua publicação. Após a conclusão, pode haver um acompanhamento ${ }^{19}$ das iniciativas acordadas pelas partes durante a mediação ou de recomendaçóes emitidas pelo PCN na declaraçáo final (Brasil, 2020b).

Quanto aos aspectos práticos de tratamento das instâncias, o PCN Brasil confirma o recebimento das alegaçóes e solicita comentários das partes durante a conclusão dos procedimentos, quando elas são convidadas a revisar a declaração final (Brasil, 2020a). Nos itens referentes à mediação, foram raras as mediaçóes conduzidas pelo PCN até hoje e também os treinamentos realizados para

\footnotetext{
14. Ver capítulo 4 de Brasil (2020b).

15. Ver capítulo 5 de Brasil (2020b).

16. Ver capítulo 6 de Brasil (2020b).

17. Ver capítulo 7 de Brasil (2020b).

18. Para a OCDE, as instâncias podem ser encerradas por meio de um comunicado, caso a conclusão ocorra ainda durante a avaliação inicial, caso uma das partes não aceite a oferta de bons ofícios ou caso não se chegue a um acordo durante a mediação; ou de um relatório, caso as partes cheguem a um acordo (OECD, 2011).

19. Informações detalhadas disponíveis no capítulo 8 de Brasil (2020b).
} 
o aperfeiçoamento da equipe em relação ao tema (Brasil, 2013b; 2014; 2015; 2016a; 2017; 2018; 2019b; 2020a).

Por fim, quanto ao reporte das instâncias específicas, o PCN Brasil publica informaçóes sobre os procedimentos (em português e em inglês) e o andamento das instâncias em sua página eletrônica e as envia para a atualização da base de dados de instâncias específicas da OCDE (Brasil, 2020a). O PCN Brasil ultrapassa com frequência o prazo de doze meses para a conclusão das instâncias específicas (Brasil, 2021), ponto que discutiremos nos desafios. Quanto às atividades de acompanhamento das recomendaçóes realizadas pelo PCN após o fim da instância específica, eram realizadas de forma errática, mas ganharam um procedimento específico na última atualização procedimental (Brasil, 2020b).

\subsection{Coerência política em CER}

A coerência política já estava implicitamente entre as funções dos PCNs, mas vem sendo enfatizada desde 2019, quando houve o estabelecimento de um mandato no GT de CER da OCDE para o tema. Esse papel ativo na promoção da coerência política em CER é visto como parte de promoção das Diretrizes, ainda que tenha desenho próprio. Tal atuação seria importante para assegurar posiçóes governamentais efetivas e coesas diante da natureza multifacetada da CER (OECD, 2019).

De acordo com a OCDE, quando os PCNs desempenham esse papel ativo na promoção de coerência política, as abordagens governamentais para a CER são fortalecidas e a visibilidade dos PCNs como uma "autoridade em CER" em seus países é intensificada (OECD, 2019). A organização explica que os PCNs podem promover essa coerência com os entes governamentais também por meio do tratamento das instâncias específicas, ao informar outras agências sobre questôes das declaraçóes finais que sejam relevantes para os programas e as políticas das agências, algo que já está previsto nas Diretrizes (OECD, 2020b).

O Questionário passa a tratar de coerência política a partir de 2016. Os PCNs são chamados a informar sobre: i) referências às Diretrizes em legislação nacional; ii) adoção ou desenvolvimento de plano de ação nacional; iii) divulgação dos comunicados e relatórios das instâncias específicas no governo; iv) açôes sobre CER e compras públicas; e v) outros exemplos de coerência política em CER.

\subsubsection{Avanço da implementação no Brasil}

No que diz respeito a referências às Diretrizes em legislaçôes nacionais, pouco foi informado nos últimos anos, sendo os mais relevantes: o Decreto no 9.571, de 21 de novembro de 2018, que estabelece as Diretrizes Nacionais sobre Empresas e Direitos Humanos, e a Resolução Coninv no 2, de 22 de dezembro de 2020, que aprova o mandato para a elaboração do Plano de Ação em Conduta Empresarial Responsável (Brasil, 2020c).

Quanto à adoção ou ao desenvolvimento de um Plano de Ação Nacional, em alguns anos o PCN relatou que sim, em outros que não (Brasil, 2013b; 2014; 2015; 2016a; 2017; 2018; 2019b; 2020a). De fato, em 2018, o Brasil publicou o decreto citado sobre direitos humanos e empresas, mas ainda não lançou um plano de ação nacional em direitos humanos em empresas, conforme o previsto pelos Princípios Orientadores da ONU. Quanto à CER, em dezembro de 2020, foi aprovado um mandato para o desenvolvimento do Plano de Ação em CER (Pacer) pelo PCN, no âmbito do Coninv, o qual deve ser concluído até agosto de 2022 (Brasil, 2020c). 
Em relação à divulgação dos comunicados e relatórios das instâncias específicas emitidos pelo PCN para os servidores responsáveis por missóes comerciais, incentivos ao comércio e investimentos estrangeiros e compras públicas, também há divergência nos reportes entre os Questionários (Brasil, 2013b; 2014; 2015; 2016a; 2017; 2018; 2019b; 2020a). De todo modo, sabemos que parcela significativa dessas partes interessadas tem acesso a essas informaçôes por pertencer aos colegiados do PCN ou do Coninv, mas parece haver espaço para açóes adicionais.

Por fim, as compras públicas vêm sendo enfatizadas pela OCDE como um dos principais locus em que os governos podem usar sua influência para incentivar a CER. Desde 2018, há uma seção específica no Questionário sobre compras públicas, com maior ênfase em 2019 e $2020 .{ }^{20}$ Nesses dois últimos anos, o PCN Brasil reportou estar em diálogo e colaboração com os responsáveis por compras públicas no governo para impulsionar a agenda de CER, além de relatar outras açóes desenvolvidas pelos membros do GTI do PCN nessa seara (Brasil, 2018; 2019b; 2020a).

Finalizamos assim a breve análise sobre a estrutura, o arranjo institucional e as principais funçóes dos PCNs, observando o avanço da implementação no Brasil. Na seção seguinte, partimos das informaçóes apresentadas para explorar alguns dos desafios e oportunidades para a atuação do PCN Brasil.

\section{DESAFIOS E OPORTUNIDADES PARA A ATUAÇÃO DO PCN BRASIL}

Nesta seção, exploramos alguns dos desafios e oportunidades para a atuação do PCN Brasil seguindo a mesma estrutura utilizada na seçáo anterior. Iniciamos partindo da análise sobre sua estrutura e seu arranjo institucional, passamos por promoção das Diretrizes e instrumentos relacionados, pelo tratamento das instâncias específicas, e finalizamos com a coerência política em CER. Os desafios foram identificados pela análise das respostas ao Questionário em contraste com aqueles apontados pela OCDE no documento National Contact Points for Responsible Business Conduct: providing access to remedy 20 years and the road ahead (OECD, 2020b), que realiza um balanço dos vinte anos de atuação dos PCNs como mecanismo de reclamação.

\subsection{Estrutura e arranjo institucional}

\section{QUADRO 1}

Desafios e oportunidades na estrutura e no arranjo institucional do PCN Brasil

\begin{tabular}{|l|l|}
\hline \multicolumn{1}{|c|}{ Desafios } & \multicolumn{1}{c|}{ Oportunidades } \\
\hline & - Institucionalização \\
- Alta rotatividade de funcionários & - Estabelecimento de órgão consultivo \\
- Subutilização do GTI do PCN & - Treinamento \\
- Falta de recursos humanos e financeiros & - Revisãa das regras para designação de membros do GTI do PCN \\
& - Automatização do tratamento das instâncias \\
& - Otimização das parcerias \\
\hline
\end{tabular}

Elaboração da autora.

20. Questiona-se sobre menção às Diretrizes, ao PCN ou a instrumentos de devida diligência da OCDE na legislação nacional de compras públicas; consultas ao PCN pelos responsáveis por compras públicas; participação dos responsáveis por compras públicas em treinamento ou atividades de promoção; ferramentas ou atividades do PCN para dar suporte aos responsáveis por compras públicas em relação a CER e devida diligência; boas práticas envolvendo compras públicas e CER (Brasil, 2020a). 


\subsubsection{Alta rotatividade de funcionários}

No que diz respeito ao arranjo institucional do PCN, um primeiro desafio facilmente identificado é o da descontinuidade diante das alteraçóes na equipe responsável pela Coordenação e pela Secretaria Executiva do PCN, além dos membros titulares e suplentes no GTI. A OCDE aponta que alteraçóes excessivas de equipe são problemáticas, dado que drenam recursos dos PCNs por frequentes necessidades de treinamento, além de atrapalhar o relacionamento com as partes interessadas (OECD, 2020b). A organização conclui que limitar essa rotatividade pode ser um modo efetivo de reduzir atrasos no tratamento das instâncias específicas, construir expertise e ganhar confiança.

Analisando os Questionários referentes ao período de 2012 a 2020, vemos cinco alteraçóes nos responsáveis pelas respostas (em geral, o coordenador) em um período de oito anos, sem contar outras mudanças internas na equipe que não são tão facilmente identificáveis (Brasil, 2013b; 2014; 2015; 2016a; 2017; 2018; 2019b; 2020a). Ao analisar os dados de promoção e tratamento de instâncias específicas, será possível notar que há uma queda na performance do PCN a cada nova equipe responsável, demandando um tempo para reorganização, aprendizado e, muitas vezes, alteraçóes nos procedimentos.

A rotatividade de funcionários é uma questão mais ampla no governo, de difícil resolução isolada para o caso específico do PCN. Oportunidades vislumbradas seriam tornar as transiçôes, muitas vezes inevitáveis, mais brandas - por exemplo, ter treinamentos-padrão a serem realizados com novos funcionários da equipe (da Coordenação, da Secretaria Executiva, do GTI) pode ser útil. O mesmo se aplica a documentos que orientem e descrevam as rotinas de trabalho e esclareçam as funçóes entre os diferentes atores envolvidos nas atividades do PCN. Esses aperfeiçoamentos contribuiriam também para a institucionalização do PCN e para a retenção da confiança das partes interessadas.

Especificamente no que diz respeito ao relacionamento com as partes interessadas, o estabelecimento de órgão consultivo, conforme sugerido pela OCDE, pode ser útil (OECD, 2020b). Assim, o diálogo com atores estratégicos para o PCN deixaria de ocorrer de forma ad hoc e depender das pessoas que estão na gestão naquele momento, despendendo menos recursos para a reconstrução dessas parcerias a cada alteração na gestão do PCN.

\subsubsection{Subutilização do GTI}

Em relação ao formato interministerial, notamos que o GTI apresenta vantagens potenciais em relação às três funçôes principais dos PCNs:

- quanto à promoçãa, os membros do GTI podem expandir a visibilidade do PCN e promover as Diretrizes em seus temas e setores;

- quanto às instâncias específicas, garantem maior imparcialidade no tratamento e trazem sua expertise como relatores no tratamento dos casos; e

- quanto à coerência política, o GTI poderia se firmar como um dos principais locus de coordenação das políticas de CER no Brasil.

Entre os desafios que esse formato traz, a OCDE chama a atenção para a falta de uma clara definição de papéis, o que pode limitar visibilidade, acessibilidade, transparência e accountability do PCN (OECD, 2020). No Brasil, um primeiro desafio associado a essa questáo é fazer com que o 
grupo interministerial de fato contribua com as funçóes citadas, justificando o ônus administrativo que a gestão do colegiado representa para a Secretaria Executiva do PCN. Os titulares e suplentes de cada órgão não possuem dedicação exclusiva nem há uma predeterminação em decreto que associe essa representação a determinada função na instituição. Assim, aqui também a alta rotatividade pode se tornar um empecilho.

Como no caso da equipe da Coordenação e da Secretaria Executiva, acreditamos que a melhor definição de papéis e a realização de treinamentos auxiliariam a otimizar a presença do GTI no PCN. Retirar barreiras referentes à titularidade dos membros, que foram incluídas por meio do Decreto no 9.874/2019, também poderia ser útil. Dessa maneira, seria possível que os órgãos designassem técnicos especializados nos temas em discussão no $\mathrm{PCN}$ em vez de gestores de alto nível, que são alterados com mais frequência e muitas vezes não têm o interesse ou o tempo necessário para a dedicação às demandas do colegiado.

\subsubsection{Falta de recursos humanos e financeiros}

Também há desafios relevantes em relação aos recursos humanos e financeiros disponíveis para as atividades do PCN. De acordo com a OCDE, limitaçóes em relação à falta de pessoal são reportadas frequentemente nos relatórios anuais sobre os $\mathrm{PCN}$ e nos peer reviews. A organização aponta que esse é primeiro ponto a ser endereçado pelos governos para o fortalecimento de seus PCNs (OECD, 2020b).

Como vimos, o PCN Brasil tem uma equipe com dedicação exclusiva e teve aumento no número de integrantes nos últimos anos (Brasil, 2013b; 2014; 2015; 2016a; 2017; 2018; 2019b; 2020a). Porém, os desafios que veremos a seguir em relação ao extensivo trabalho necessário na promoção, ao grande número de instâncias específicas e às demandas crescentes quanto à coerência política e ao relacionamento com a própria OCDE fazem com que a equipe disponível pareça permanecer insuficiente.

Além disso, é preciso que os PCNs tenham os recursos financeiros necessários para realizar atividades promocionais customizadas e treinamentos, e lidar de modo efetivo com as instâncias específicas - por exemplo, arcando com custos de treinamento avançado em mediação ou contratação de mediadores, tradução e locomoção (OECD, 2020b). O PCN Brasil está entre os 31 PCNs que não têm um orçamento próprio (op. cit.) e reporta frequentemente nos Questionários não ter tido recursos financeiros suficientes para executar todas as atividades esperadas (Brasil, 2015; 2016a; 2017; 2018; 2019b; 2020a).

Algumas das ações enumeradas ao tratar do desafio da alta rotatividade de funcionários podem ajudar na utilização dos recursos humanos e financeiros, ao reduzir o retrabalho. Outra medida seria automatizar o máximo possível das atividades de secretariado das instâncias específicas, tendo, por exemplo, um sistema que realizasse e documentasse o recebimento e o encaminhamento de documentos, controlasse os prazos etc. No que diz respeito à promoçáo, algumas das açóes propostas no item seguinte, sobretudo quanto às parcerias, também poderiam auxiliar a potencializar o uso dos recursos disponíveis. 


\subsection{Informação e promoção das Diretrizes da OCDE e instrumentos relacionados}

\section{QUADRO 2}

Desafios e oportunidades na informação e na promoção pelo PCN Brasil

\begin{tabular}{|l|l|}
\hline \multicolumn{1}{|c|}{ Desafios } & \multicolumn{1}{c|}{ Oportunidades } \\
\hline - Baixo número de atividades de promoção & - Eventos virtuais \\
- Pouca capilaridade das atividades de promoção & - Utilização do GTI do PCN e do Coninv \\
- Deficiências na customização das atividades de promoção para perfis e setores empresariais & - Reconstrução, ampliação e utilização estratégica das parcerias \\
\hline
\end{tabular}

Elaboração da autora.

\subsubsection{Baixo número de atividades de promoção}

Um primeiro desafio é que o PCN Brasil realiza um número baixo de atividades de promoção, o que consideramos uma questão bastante grave, uma vez que essa é a função primordial dos PCNs. Conforme aponta a OCDE, a visibilidade é um dos critérios-chave dos PCNs (OECD, 2020b). Apenas criar um PCN não cumpre a obrigação governamental - espera-se que os governos façam seus PCNs visíveis, e os próprios PCNs também devem contribuir para sua visibilidade. Ademais, a limitação nas atividades de promoção reduz o conhecimento sobre o mecanismo de reclamação, diminuindo o número de instâncias específicas. Deficiências na área de promoção também impactam a visibilidade das açóes de CER no governo e no potencial de atuação do PCN como ferramenta para a coordenação e a coerência política em CER.

Nesse contexto, a OCDE trata de dois problemas principais: a realização de poucos eventos de forma geral; ou a realizaçáo de eventos que não enderecem adequadamente todas as partes interessadas relevantes (OECD, 2020b), do qual trataremos no item seguinte.

O PCN Brasil tem um número bastante irregular e, em geral, baixo de atividades promocionais (gráfico 1). De 2012 a 2014, há reporte de que o PCN organizou ou coorganizou e participou como palestrante em diversos eventos, buscando divulgar as Diretrizes no Brasil junto a um conjunto de parceiros nacionais e internacionais ${ }^{21}$ (Brasil, 2013b; 2014; 2015). Na sequência, notamos uma queda no engajamento do PCN entre 2015 e 2018 no que diz respeito a eventos e reporte de parcerias (Brasil, 2016a; 2017; 2018).

Em 2019 e 2020, assistimos a um crescimento no número de eventos, que chega a seu maior nível na série observada (Brasil, 2019b; 2020a). Os relatórios apresentados ao Coninv, no primeiro e segundo semestres de 2020, também registram uma gradual retomada da construção de parcerias com as partes interessadas ${ }^{22}$ (Brasil, 2020d; 2020e).

Uma oportunidade significativa a ser aproveitada é utilizar os eventos virtuais para a divulgação das Diretrizes para públicos mais amplos, com reduzido gasto de recursos humanos e financeiros. Uma segunda abordagem a ser considerada é buscar um melhor aproveitamento dos membros

21. Nacionais: Fórum Governamental de Responsabilidade Social, Instituto Ethos, CGU, Agência Brasileira de Promoção de Exportações e Investimentos (Apex-Brasil), agências de crédito à exportação, entre outros. Internacionais: Pontos Focais do Pacto Global da ONU, Global Reporting Initiative (GRI), International Organization for Standardization (ISO) 26000, PCNs de Reino Unido, Holanda e Noruega, entre outros.

22. Pacto Global da ONU, Laboratório de Inovação Financeira (LAB), clínicas de direitos humanos da Pontifícia Universidade Católica do Paraná (PUCPR) e do Centro Universitário de Brasília (Ceub), PCN Argentina, além das parcerias no âmbito governamental que passam a ser descritas em item dedicado à "coordenação de políticas de CER" (Brasil, 2020e). 
do GTI do PCN, e também do Coninv, como disseminadores das Diretrizes. Os Questionários apresentados à $\mathrm{OCDE}$ e relatórios ao Coninv praticamente não reportam atividades desempenhadas pelos membros. Ganhos nesse sentido seriam benéficos tanto para questóes de visibilidade quanto de coerência política em CER.

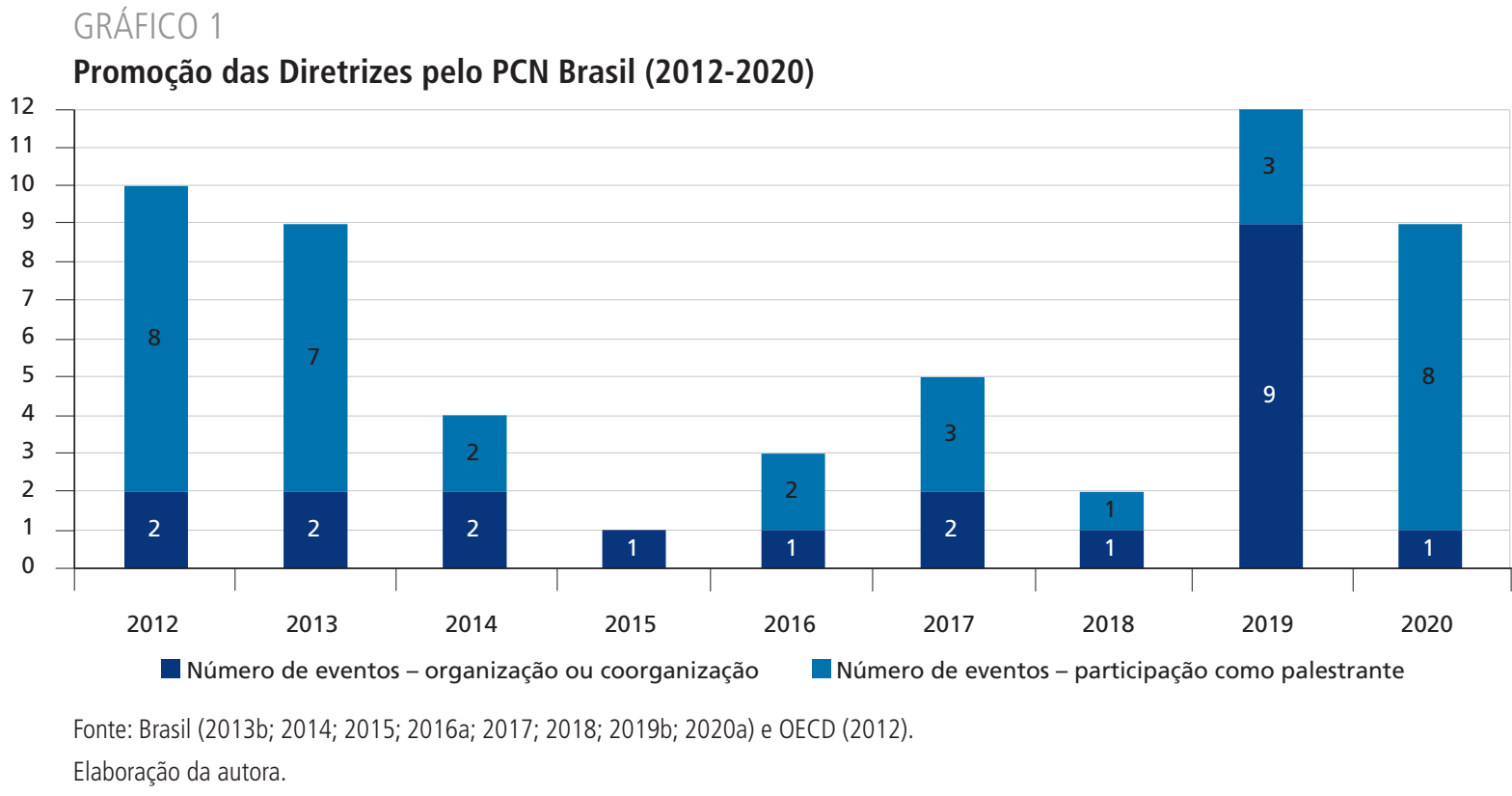

Por fim, uma terceira oportunidade que vislumbramos é retomar parcerias estratégicas com partes interessadas dentro e fora do governo brasileiro, que possam ser coorganizadoras de eventos com o PCN ou convidadas como palestrantes para eventos relacionados à CER. Ainda que a reconstrução e a manutenção das parcerias impliquem um dispêndio de recursos humanos, acreditamos que são maiores os ganhos em termos de visibilidade e confiança no PCN.

\subsubsection{Distribuição territorial das atividades de promoção}

Além do desafio em relação à quantidade de atividades promocionais, temos um adicional quanto à distribuição dessas atividades, seja territorial, por público, por setores econômicos ou temas da CER. Como vimos, a OCDE indica como um dos problemas de visibilidade dos PCNs a realização de eventos que náo enderecem adequadamente todas as partes interessadas relevantes, como é o caso de potenciais alegantes que estejam em áreas remotas (OECD, 2020b). Nesse contexto, um primeiro ponto de atenção é a grande extensão territorial do Brasil, com áreas de mais difícil acesso.

Ao analisar o registro das atividades promocionais do PCN, notamos concentraçáo em Brasília (local da estrutura física da Coordenação e da Secretaria Executiva do PCN), com São Paulo e Rio de Janeiro em seguida (Brasil, 2013b; 2014; 2015; 2016a; 2017; 2018; 2019b; 2020a; OECD, 2012). Em 2019, houve um esforço interessante de divulgação em roadshows em oito capitais brasileiras, incluindo as regióes Centro-Oeste, Nordeste, Sul e Sudeste, além de evento na regiáo Norte (Brasil, 2019b).

Em 2020, com a pandemia, os eventos passaram a ser virtuais, o que ajuda a romper as barreiras territoriais. Permanecem, porém, dificuldades para que potenciais alegantes sejam informados sobre a 
realização dos eventos e disponham das condições necessárias (como acesso à internet e equipamentos) para a participação. Uma questáo adicional é a barreira linguística, dado que muitos eventos foram realizados em línguas estrangeiras (Brasil, 2020a).

Mais uma vez, no que diz respeito à capilaridade das atividades promocionais do PCN, acreditamos que as parcerias poderiam ser um recurso valioso. $\mathrm{O} P C N$ pode se utilizar de integrantes dos colegiados governamentais e das redes com partes interessadas de que participe que tenham localização ou atuação em regiôes normalmente não cobertas por suas atividades. A Apex-Brasil, por exemplo, é membro do Coninv e já teve parcerias com o PCN no passado. Ademais, o PCN poderia acionar organizaçóes de empresas e trabalhadores nessas regióes, além de ONGs que tenham alcance nacional ou foco em regióes nas quais seja preciso ampliar sua visibilidade.

Outra oportunidade, talvez de mais fácil implementação, seria contar com o apoio da Rede de Pontos Focais do Ombudsman de Investimentos Diretos (OID). Essa estrutura se apresenta como uma "janela única de investimentos" responsável por receber consultas e questionamentos sobre matérias relacionadas a investimentos, a serem respondidos em conjunto com órgáos e entidades governamentais na esfera nacional e subnacional (Brasil, 2020f). Essa facilidade se daria porque a gestão do OID também é competência da Camex e está alocada na subsecretaria pela qual o coordenador do PCN é responsável.

\subsubsection{Customização das atividades de promoção para perfis e setores empresariais}

Indo além da dimensão territorial, no que diz respeito ao público-alvo das atividades de promoção das Diretrizes, também parece haver espaço para aperfeiçoamentos por parte do PCN Brasil. Consideramos que o principal grupo a tomar conhecimento das Diretrizes são as empresas, por isso concentramos nelas nossa análise.

Quanto ao perfil das empresas, podemos pensar em três grupos principais: multinacionais brasileiras, multinacionais estrangeiras atuando no Brasil e outras empresas nacionais. Quanto às empresas multinacionais brasileiras, virtualmente, todas as iniciativas de promoçáo comentadas atendem o público. No que diz respeito às multinacionais estrangeiras, podemos considerar que são especialmente contempladas pelos eventos organizados em parceria com atores internacionais (outros PCNs, OCDE, Uniáo Europeia etc.), sobretudo de 2012 a 2015 e em 2020 (Brasil, 2013b; 2014; 2015; 2016a; 2017; 2018; 2019b; 2020a; OECD, 2012). Ainda assim, não identificamos formatação de evento específico para esses públicos.

As empresas nacionais se apresentam como um desafio mais complexo, sobretudo para alcançar as micro, pequenas e médias empresas (MPMEs). Ainda que as Diretrizes se refiram explicitamente a empresas multinacionais, o capítulo de conceitos e princípios explica que elas trazem boas práticas recomendáveis a todas as empresas, e as empresas nacionais estão sujeitas às mesmas expectativas que as multinacionais (OECD, 2011). Além disso, as empresas nacionais fazem parte das cadeias de fornecimento de multinacionais, estando focalizadas pelo trabalho da OCDE sobre devida diligência e CER, que vimos estar ganhando peso nos últimos anos.

De acordo com dados do Instituto Brasileiro de Geografia e Estatística (IBGE) de 2015, mais de 97\% das empresas ativas no Brasil eram micro ou pequenas (Guimarães, Carvalho e Paixão, 2018). Em 2017, mais de 70\% das empresas exportadoras brasileiras eram micro (17,8\%), pequenas $(23,1 \%)$ ou médias empresas (30,2\%) (Fonseca, 2018). Mesmo com essa presença tão significativa, os dados não 
demonstram a realização de qualquer evento do PCN Brasil de 2012 a 2020 tendo como público-alvo as MPMEs (Brasil, 2013b; 2014; 2015; 2016a; 2017; 2018; 2019b; 2020a; OECD, 2012).

Outro desafio é o alcance setorial. Analisando os dados de 2012 a 2020, aparecem apenas dois eventos claramente direcionados a setores específicos: um para o setor financeiro em 2014 e um para o setor têxtil em 2015 (Brasil, 2013b; 2014; 2015; 2016a; 2017; 2018; 2019b; 2020a). Portanto, um possível aperfeiçoamento seria o PCN passar a desenvolver atividades de promoção para setores específicos - por exemplo, os mais endereçados nas instâncias específicas recebidas em determinado período ou os que são alvo de recomendaçóes ou orientaçóes particulares pela OCDE, como os guias setoriais de devida diligência em CER.

Olhando para as oportunidades, no que diz respeito às multinacionais brasileiras e estrangeiras, são um público que poderia ser explorado em parceria com as embaixadas (do Brasil no exterior e de outros países, sobretudo os aderentes às Diretrizes, no Brasil) e com PCNs estrangeiros. Quanto às empresas nacionais, mais uma vez, vemos a oportunidade de melhor utilização dos membros do próprio GTI do PCN. Um exemplo seria a CGU, que tem parceria consolidada com o Serviço Brasileiro de Apoio às Micro e Pequenas Empresas (Sebrae) para a promoção da integridade para MPMEs, agenda na qual a discussão sobre as Diretrizes poderia ser facilmente inserida.

Também enxergamos uma oportunidade de alcançar as empresas nacionais por meio de atividades e parcerias que enderecem as multinacionais, levando em consideração o papel dessas empresas de disseminar boas práticas e mitigar riscos relacionados às empresas que compóem sua cadeia de fornecimento. Essa interação poderia ser feita por meio de treinamentos para a comunidade empresarial ou reunióes multistakeholder, duas iniciativas nas quais o PCN Brasil não vem apresentando bons resultados nos Questionários e que parecem relevantes para sua visibilidade e para a eficácia da implementação das Diretrizes no país.

\subsection{Tratamento de instâncias específicas de inobservância das Diretrizes}

QUADRO 3

Desafios e oportunidades no tratamento de instâncias específicas pelo PCN Brasil

\begin{tabular}{|l|l|}
\hline \multicolumn{1}{|c|}{ Desafios } & \multicolumn{1}{c|}{ Oportunidades } \\
\hline $\begin{array}{l}\text { - Baixo número de alegações de inobservância recebidas } \\
\text { - Baixo percentual de realização de bons ofícios } \\
\text { - Dificuldade de atender aos prazos }\end{array}$ & $\begin{array}{l}\text { - Ampliação da visibilidade } \\
\text { - Aprofundamento da confiança } \\
\text { - Conscientização sobre o objetivo do mecanismo } \\
\text { - Automatização do mecanismo }\end{array}$ \\
\hline
\end{tabular}

Elaboração da autora.

\subsubsection{Baixo número de alegações de inobservância recebidas}

No que diz respeito às instâncias específicas, o primeiro desafio é o baixo número de alegaçóes de inobservância recebidas, considerando o tamanho e a inserção internacional do Brasil. Nesse contexto, apesar de o PCN Brasil ser um dos países aderentes que têm um maior número total de instâncias, ainda há o recebimento de um número baixo de alegaçóes de inobservância. Essa é uma realidade que afeta toda a Rede dos PCNs e está relacionada à acessibilidade, um dos critérios de equivalência funcional dos PCNs.

De acordo com a OCDE, dizer que os PCNs devem ser acessíveis representa que sua utilização como mecanismo de reclamação deve ser simples e não muito onerosa (OECD, 2021b). A organização 
reconhece que os PCNs vêm adotando estratégias para assegurar essa acessibilidade, mas ainda há barreiras. Um ponto de partida é que os potenciais alegantes precisam conhecer o mecanismo para que apresentem alegaçôes. Assim, as dificuldades de visibilidade sobre as quais comentamos no item anterior contribuem para a manutençáo dos casos em números relativamente baixos (OECD, 2020b).

Buscamos analisar se seria possível verificar essa relaçáo no Brasil no período analisado, de 2012 a 2020. No gráfico 1, observamos que o PCN realizou mais atividades de promoção de 2012 a 2014 e em 2019 e 2020. No gráfico 2, relacionamos essa informaçáo com a de recebimento de novas alegações de inobservância.

GRÁFICO 2

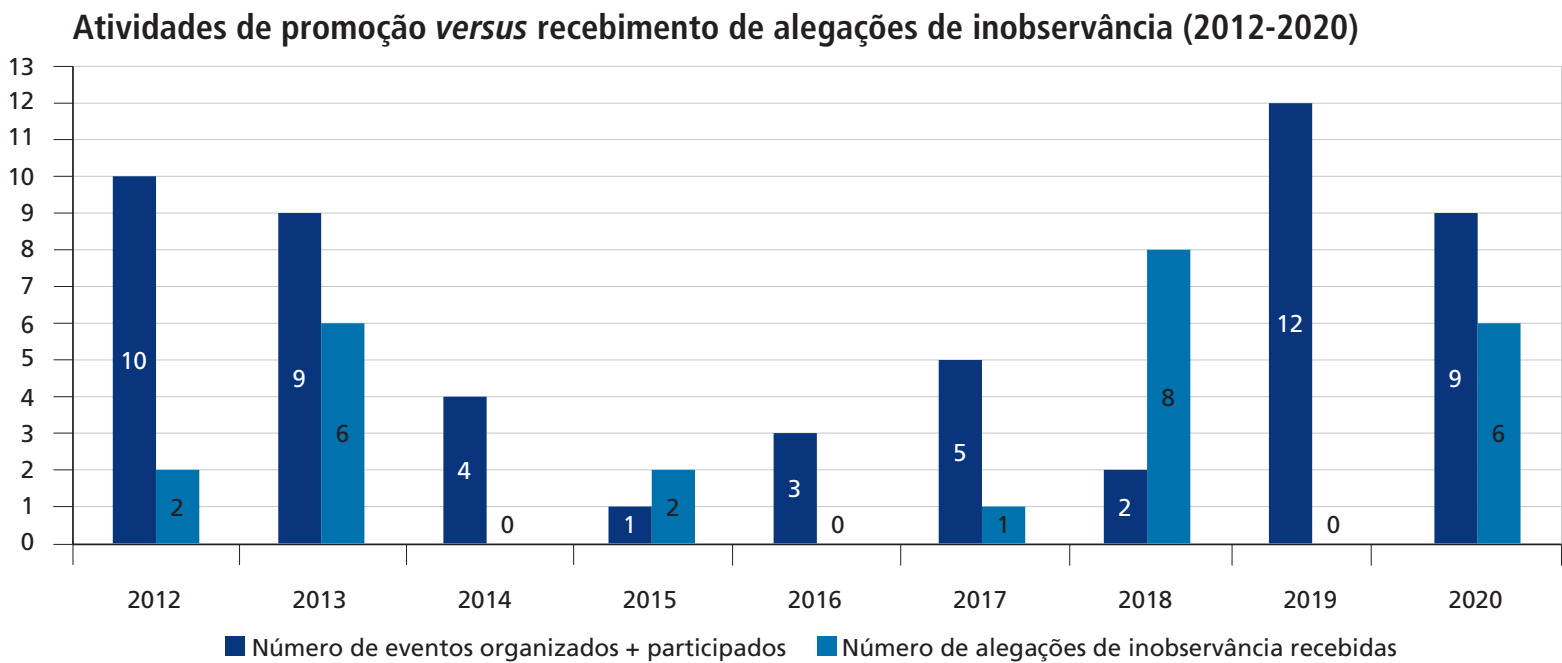

Fonte: Brasil (2013b; 2014; 2015; 2016a; 2017; 2018; 2019; 2020a; 2021) e OECD (2012).

Elaboração da autora.

Ao observar o gráfico, percebemos picos nas alegaçóes de inobservância recebidas em 2013, 2018 e 2020, com recebimento de zero a duas notificaçôes nos outros anos. Também notamos uma queda no número de atividades promocionais do PCN no período de 2014 a 2018. Porém, não foi possível identificar correlação exata entre número de atividades promocionais realizadas e alegaçóes recebidas, inclusive pelo possível efeito de que a divulgação do mecanismo motive o envio de alegação apenas em anos seguintes.

Há ainda outras questóes a serem consideradas para o recebimento de alegaçóes além da visibilidade - entre elas, podemos destacar a confiança depositada pelos alegantes no mecanismo. A queda significativa no número de alegaçóes de inobservância recebidas de sindicatos a partir de 2014 (gráfico 3) pode ser um indicativo dessa quebra de confiança. ${ }^{23}$ Por sua vez, o aumento de alegaçóes enviadas por indivíduos pode ser um bom indicativo de aumento de visibilidade do PCN e de que as regras de procedimentos estão claras o suficiente para não impor barreiras de entrada a esse público, preocupação também apontada pela $\mathrm{OCDE} .{ }^{24}$

23. Outras razões a serem consideradas são a ausência de eventos específicos endereçando esse setor nos últimos anos, a insatisfação com os resultados dos casos apresentados ao PCN, entre outras.

24. A OCDE explica que os indivíduos são o grupo mais afetado pela falta de acessibilidade dos PCNs (OECD, 2020b, p. 29). 
GRÁFICO 3

Número de instâncias específicas por alegante (2003-2020)

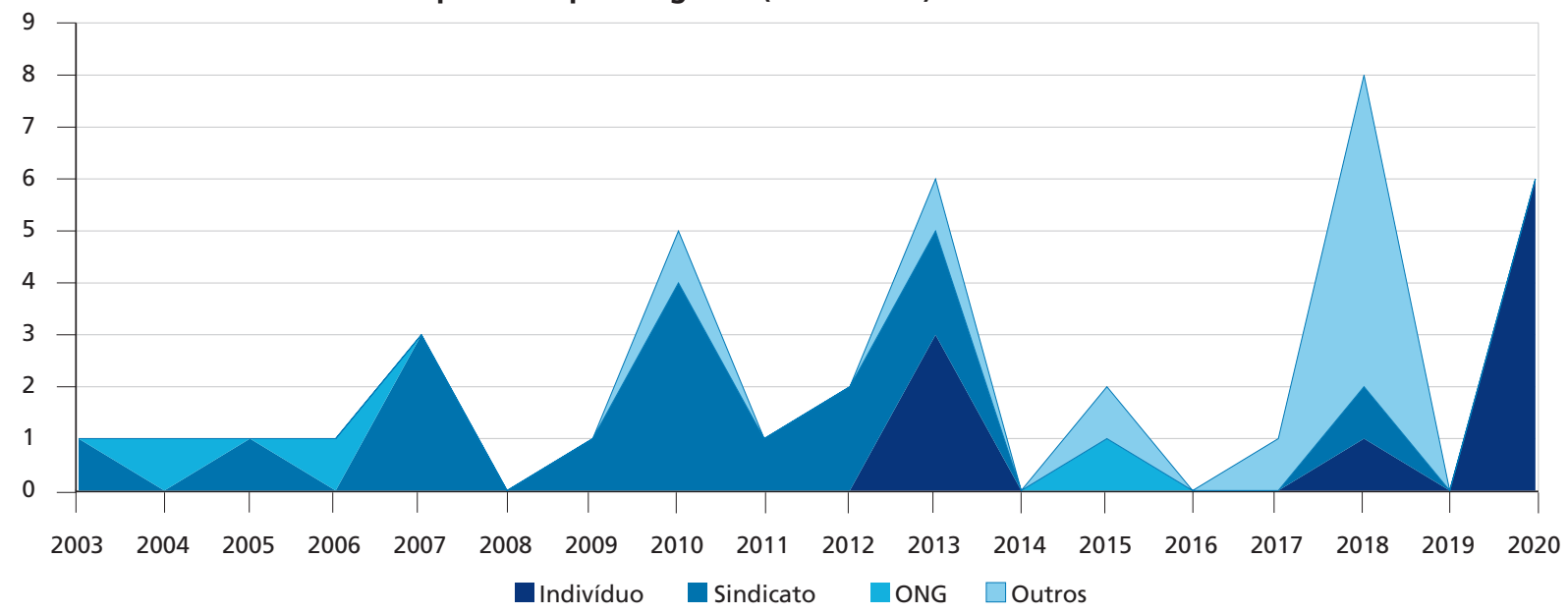

Fonte: Brasil (2021).

Elaboração da autora.

No campo das oportunidades, vislumbramos que melhorias na visibilidade do PCN atacando os desafios relacionados à promoção trarão resultados também no que diz respeito às instâncias. Quanto à confiança das partes interessadas, o PCN Brasil já vem adotando algumas medidas para endereçar a questão. Sempre há, por exemplo, um funcionário da alta administração como coordenador, que presta contas diligentemente ao Coninv, à OCDE e publica esses relatórios em sua página eletrônica, dá transparência aos procedimentos e instâncias específicas, entre outros. Porém, outras medidas, como a criação do órgão consultivo que comentamos anteriormente, pode fortalecer esse movimento.

Além disso, um contato mais direto com as partes interessadas pode auxiliar na visibilidade e na confiança, como a reunião multistakeholder mencionada no Questionário. Especificamente no que diz respeito a potenciais alegantes, acreditamos que reunióes e eventos específicos, por exemplo, com sindicatos e/ou ONGs, serão bastante úteis. Nesses encontros, o $\mathrm{PCN}$ poderia apresentar os procedimentos, tirar dúvidas sobre o funcionamento e também escutar críticas e sugestóes para o aperfeiçoamento do mecanismo.

\subsubsection{Baixo percentual de realização de bons ofícios}

Avançando nas etapas de tratamento das instâncias específicas, chegamos a um desafio que é ainda mais emblemático para o PCN Brasil: o baixo número de casos em que a etapa de bons ofícios, objetivo principal das instâncias, efetivamente ocorre. O objetivo dos PCNs é auxiliar na resolução de questôes relacionadas à implementação das Diretrizes, e eles fazem isso por meio dos bons ofícios, mais especificamente por meio da condução de procedimentos de mediação ou conciliação. Entretanto, ao olharmos os números, vemos que o PCN Brasil não é muito efetivo nesse critério.

De acordo com a OCDE, ao pensarmos na acessibilidade do mecanismo dos PCNs, devemos considerar não apenas as barreiras para a submissão da alegação de inobservância, mas também as de acesso aos bons ofícios. A organização reporta que, de 2000 a 2019, 36\% dos casos da Rede dos PCNs não passaram da avaliação inicial (OECD, 2020b). No caso do PCN Brasil, os números são bem piores: mais de 75\% dos casos foram encerrados sem a realização de bons ofícios (Brasil, 2021). 
Identificamos duas principais tendências no Brasil ao olhar esse alto percentual. A primeira é a de que o PCN oferece os bons ofícios poucas vezes, o que pode indicar dificuldades de entendimento por parte dos gestores do mecanismo de que esse é seu objetivo principal e não é necessário esgotar questóes na avaliação inicial. A segunda é a de que, quando o PCN oferta os bons ofícios, em grande parte das vezes as empresas não aceitam e os casos se encaminham para conclusão (Brasil, 2021).

Quanto às oportunidades, acreditamos que a primeira é a conscientização de que realizar os bons ofícios do PCN é o objetivo principal do mecanismo, e isso deve ser feito sempre que houver possibilidade. Esse esclarecimento pode ser realizado por meio de treinamentos à equipe do PCN, os quais estão contemplados também no eixo de estrutura e arranjo institucional. Já a aceitação da oferta de bons ofícios por parte das empresas é uma questão mais complexa, que envolve outros fatores. De todo modo, acreditamos que aperfeiçoamentos relacionados à visibilidade e à confiança no PCN podem ampliar os números de aceitação.

\subsubsection{Dificuldade de atender aos prazos}

Por fim, o último desafio que consideramos relevante discutir no âmbito das instâncias específicas é atender aos prazos indicativos com o total de doze meses para conclusão. De acordo com a OCDE, é esperado que os PCNs tratem as instâncias de modo eficiente e tempestivo. A organizaçáo reconhece que os prazos indicativos para as instâncias são relativamente curtos quando comparados aos de outros procedimentos, sobretudo os judiciais. Essa agilidade, porém, é uma das vantagens de trazer um caso ao PCN, por sua versatilidade e habilidade de agir de forma eficiente, com procedimentos simplificados (OECD, 2020b).

Dificilmente o PCN Brasil consegue concluir instâncias específicas dentro do período indicativo, sobretudo quando ocorre a etapa de bons ofícios. Os procedimentos de avaliação inicial mais demorados, que incluem a etapa não prevista pela OCDE de análise de admissibilidade, quase sempre levam mais que os três meses previstos e já inviabilizam o cumprimento do prazo total. Entretanto, a grande maioria das instâncias leva mais de dois anos para ser concluída (Brasil, 2021), o dobro do prazo total, o que indica a possível existência de pontos de retenção também em outras etapas do procedimento.

Conforme aponta a OCDE, muitos fatores impactam esses atrasos, como a complexidade dos casos, a responsividade das partes, a agenda para a realização de reuniôes, entre outros (OECD, 2020b). Ademais, dificuldades adicionais estão colocadas no contexto da pandemia. No entanto, a falta de recursos humanos para lidar com as instâncias também é um desafio considerado pela organização e importante para o contexto do Brasil, como discutimos anteriormente.

Consideramos que uma oportunidade a ser explorada, que poderia dar muito mais agilidade ao tratamento das instâncias, é a construção de um sistema automatizado que tire parte do ônus administrativo da Secretaria Executiva e agilize a comunicação entre as partes envolvidas. Entendemos que a automatizaçáo poderia trazer, ainda, benefícios adicionais em termos de previsibilidade, transparência e mesmo na confiança e credibilidade do mecanismo. 


\subsection{Coerência política em CER}

QUADRO 4

Desafios e oportunidades para coerência política em CER pelo PCN Brasil

\begin{tabular}{|l|l|}
\hline \multicolumn{1}{|c|}{ Desafios } & \multicolumn{1}{c|}{ Oportunidades } \\
\hline & - Explorar parcerias com instituições nacionais de direitos humanos (INDHs), escritórios de organizações internacionais, embaixadas, \\
- Falta de recursos humanos & $\begin{array}{l}\text { agências governamentais } \\
\text { - Utilização do GTI do PCN e do Coninv } \\
\text { - Criação de órgão multistakeholder }\end{array}$ \\
\hline
\end{tabular}

Elaboração da autora.

Por fim, no que diz respeito à coerência política, o desafio principal é que a equipe do PCN tenha recursos humanos suficientes para exercer essa função adicional. Mas talvez seja também a área em que há mais oportunidades a serem exploradas, com ganhos que podem transbordar para as funçôes de promoção (com ampliação da visibilidade do PCN) e de tratamento das instâncias específicas (com aumento da confiança no PCN e utilização dos resultados das instâncias por outras agências governamentais).

A OCDE aponta que há riscos de incoerência quando há falta de comunicação sobre as Diretrizes e o papel do PCN no âmbito do governo (OECD, 2019). Esse problema seria especialmente grave dada a coexistência de instrumentos internacionais de CER (como os Princípios Orientadores da ONU e a Declaração Tripartite da OIT), muitas vezes de responsabilidade de ministérios diferentes.

São oportunidades para a ampliação da coordenação e da coerência em CER, mas também para a promoção das Diretrizes, uma maior integração e uma melhor utilização por parte do PCN de parcerias com:

- INDHs;

- escritórios das organizaçóes internacionais, como a Rede Brasil do Pacto Global, os escritórios da ONU, da OIT e da Uniáo Europeia, o Ponto Focal da GRI no Brasil, entre outros;

- embaixadas estrangeiras no Brasil e brasileiras no exterior;

- colegiados, como o GTI do PCN e o Coninv; e

- outras agências governamentais, como as responsáveis por crédito e garantia às exportações e ao financiamento ao desenvolvimento.

Além disso, o PCN poderia considerar a criação do órgão multistakeholder, expandindo essa coordenação para atores náo governamentais.

\section{CONSIDERAÇÕES FINAIS}

Esperamos neste artigo ter fornecido ao leitor um panorama sobre o funcionamento dos PCNs, com foco no PCN Brasil. Buscamos, ainda, ter levado a reflexóes sobre alguns desafios e oportunidades relevantes para a atuação do PCN no que diz respeito a quatro áreas principais: estrutura e arranjo institucional; informaçáo e promoção; tratamento das instâncias específicas; e coerência política em 
CER. Sabemos que muitos outros temas poderiam ter sido explorados, sendo aqueles selecionados a partir da experiência da autora na equipe do PCN Brasil em dois diferentes períodos.

Nestas breves consideraçóes finais, chamamos ainda a atenção para dois movimentos já em curso e que podem impactar a implementação das Diretrizes e a atuação do PCN nas próximas décadas. O primeiro é a pandemia do coronavírus, que ainda estamos vivendo e que certamente traz, além das perdas irreparáveis, seus próprios desafios e oportunidades. O segundo é o exercício em curso de stocktaking (levantamento) das Diretrizes, que tem como objetivo verificar se elas continuam adequadas para os desafios atuais e dos próximos anos e que possivelmente levará a uma nova revisão. Nossa esperança é que as Diretrizes e o PCN reafirmem sua importância nesse novo cenário, contribuindo para a construção de um ambiente de negócios em que a conduta empresarial responsável seja o comportamento padrão.

\section{REFERÊNCIAS}

BRASIL. Ministério da Fazenda. Portaria no 92, de 12 de maio de 2003. Aprova a criação do Ponto de Contato Nacional segundo as diretrizes para as multinacionais - OCDE. Diário Oficial da Uniáo, Brasília, p. 12, 14 maio 2003. Disponível em: <https://bit.ly/3iDTPl0>. Acesso em: 25 fev. 2021.

. Resoluçáo PCN no 1 , de 14 de setembro de 2012. Dispóe sobre a atuação do Ponto de Contato Nacional. Diário Oficial da Uniáo, Brasília, 27 set. 2012.

Portaria Interministerial no 37, de 19 de fevereiro de 2013. Dispóe sobre a estrutura e organizaçáo do Ponto de Contato Nacional para as Diretrizes da Organizaçáo para Cooperaçáo e Desenvolvimento Econômico (OCDE) para as Empresas Multinacionais. Diário Oficial da Uniáo, Brasília, n. 34, p. 42, 20 fev. 2013a. Seção 1.

Ministério da Economia. OECD Guidelines for Multinational Enterprises: report to the OECD 2013. Brasília: ME, 2013b. Disponível em: <https://bit.ly/3v9WpC9>. Acesso em: 28 fev. 2021.

Ministério da Economia. Diretrizes da OCDE para as Empresas Multinacionais: relatório do Ponto de Contato Nacional do Brasil à OCDE - 2014. Brasília: ME, 2014. Disponível em: <https://bit. ly/3cxetj5>. Acesso em: 28 fev. 2021.

Ministério da Economia. Diretrizes da OCDE para as Empresas Multinacionais: relatório do Ponto de Contato Nacional do Brasil à OCDE - junho de 2014 a dezembro de 2015. Brasília: ME, 2015. Disponível em: <https://bit.ly/3xfg8BB>. Acesso em: 28 fev. 20201.

Ministério da Economia. Relatório anual do Ponto de Contacto Nacional (2016). Brasília: ME, 2016a. Disponível em <https://bit.ly/3pEXwIQ>. Acesso em: 28 fev. 2021.

Ministério da Economia. Resoluçáo PCN no 1, de 16 de novembro de 2016. Dispóe sobre a atuação do Ponto de Contato Nacional. Brasília: ME, 2016b. Disponível em: <https://bit.ly/3v68esR>. Acesso em: 28 fev. 2021.

Ministério da Economia. Relatório anual do Ponto de Contacto Nacional (2017). Brasília: ME, 2017. Disponível em: <https://bit.ly/3gsCQjf>. Acesso em: 28 fev. 2021.

. Ministério da Economia. Relatório anual do Ponto de Contacto Nacional (2018). Brasília: ME, 2018. Disponível em: <https://bit.ly/2RMdmVG>. Acesso em: 28 fev. 2021.

Decreto no 9.874, de 27 de junho de 2019. Institui grupo de trabalho interministerial denominado Ponto de Contato Nacional para a implementação das Diretrizes da Organização para Cooperação e Desenvolvimento Econômico para as Empresas Multinacionais. Diário Oficial da Uniáo, Brasília, n. 123, p. 13, 28 jun. 2019a. Seção 1. 
Ministério da Economia. Questionário do relatório anual do Ponto de Contato Nacional 2019. Brasília: ME, 2019b. Disponível em: <https://bit.ly/3womFKc>. Acesso em: 28 fev. 2021.

Ministério da Economia. National Contact Point annual reporting questionnaire (2020). Brasília: ME, 2020a. Disponível em: <https://bit.ly/2TN4nnA>. Acesso em: 28 fev. 2021.

Resolução PCN no 1, de 3 de março de 2020. Estabelece o Manual de Procedimentos para as Instâncias Específicas do Ponto de Contato Nacional. Diário Oficial da Uniáo, Brasília, n. 43, p. 15, 4 mar. 2020b. Seção 1.

Resolução Coninv no 2, de 22 de dezembro de 2020. Aprova o mandato para a elaboração do Plano de Ação em Conduta Empresarial Responsável. Diário Oficial da Uniáo, Brasília, n. 245, p. 22, 23 dez. 2020c. Seção 1.

Ministério da Economia. Relatório 1/2020 do Ponto de Contato Nacional (PCN Brasil) apresentado ao Comitê Nacional de Investimentos (Coninv) por ocasiáo da 5a reuniáo do Coninv. Brasília: ME, 2020d. Disponível em: <https://bit.ly/3cwktsy>. Acesso em: 28 fev. 2021.

Ministério da Economia. Relatório 2/2020 do Ponto de Contato Nacional (PCN Brasil) apresentado ao Comitê Nacional de Investimentos (Coninv) por ocasiáo da 6ª reuniáo do Coninv. Brasília: ME, 2020e. Disponível em: <https://bit.ly/2RFPnHw>. Acesso em: 28 fev. 2021.

. Ministério da Economia. Ombudsman de Investimentos Diretos - OID. Brasília: ME, $2020 f$. Disponível em: <http://oid.economia.gov.br/pt/menus/8>. Acesso em 17 mar. 2021.

Ministério da Economia. Instâncias específicas - alegaçóes de inobservância das diretrizes da OCDE. Brasília: ME, 11 jan. 2021. Disponível em: <https://bit.ly/2Srub8D>. Acesso em: 28 fev. 2021.

FONSECA, P. J. As micro e pequenas empresas nas exportaçóes brasileiras: 2009-2017 Brasil. Brasília: Sebrae, 2018. 132 p. Disponível em: <https://bit.ly/2SruvUT>. Acesso em: 28 fev. 2021.

GUIMARÃeS, A.; CARVALHO, K.; PAIXÃO, L. A. Micro, pequenas e médias empresas: conceitos e estatísticas. Radar, n. 55, fev. 2018. Disponível em: <https://bit.ly/2U0vDzn>. Acesso em: 28 fev. 2021.

OECD - ORGANISATION FOR ECONOMIC CO-OPERATION AND DEVELOPMENT. OECD Guidelines for Multinational Enterprises. Paris: OECD, 2011. Disponível em: <https://bit.ly/3ylzIwz>. Acesso em: 28 fev. 2021.

Annual report on the OECD Guidelines for Multinational Enterprises 2012: mediation and consensus building. Paris: OECD, 2012. Disponível em: <https://bit.ly/3jQLKdJ>. Acesso em: 28 fev. 2021.

About the OECD Guidelines for Multinational Enterprises. OECD, 2017. Disponível em: <https:// mneguidelines.oecd.org/about/>. Acesso em: 15 mar. 2021.

Action plan to strengthen National Contact Points for responsible business conduct 2019-2021. Paris: OECD, 2019. Disponível em: <https://bit.ly/3ix3J8b>. Acesso em: 28 fev. 2021.

OECD due diligence guidance for responsible business conduct. Paris: OECD, 2020a. Disponível em: <https://bit.ly/3gt5noR>. Acesso em: 28 fev. 2021.

National Contact Points for responsible business conduct: providing access to remedy 20 years and the road ahead. Paris: OECD, 2020b. Disponível em: <https://bit.ly/3xaOxS5>. Acesso em: 28 fev. 2021.

OECD responsible business conduct. OECD, 2021a. Disponível em: <http://mneguidelines.oecd. org/>. Acesso em: 28 fev. 2021.

OECD responsible business conduct. OECD Guidelines for Multinational Enterprises. OECD, 2021b. Disponível em: <http://mneguidelines.oecd.org/mneguidelines/>. Acesso em: 28 fev. 2021. 